\title{
Evolution of Microstructure from the Surface to the Interior of Cr-Mo Steel by Water Jet Peening
}

\author{
Masataka Ijiri*, Daichi Shimonishi, Daisuke Nakagawa, Toshihiko Yoshimura \\ Tokyo University of Science, Yamaguchi, Japan \\ Email: ^ijiri@rs.tusy.ac.jp
}

How to cite this paper: Ijiri, M., Shimonishi, D., Nakagawa, D. and Yoshimura, T. (2017) Evolution of Microstructure from the Surface to the Interior of Cr-Mo Steel by Water Jet Peening. Materials Sciences and Applications, 8, 708-715.

https://doi.org/10.4236/msa.2017.810050

Received: August 3, 2017

Accepted: September 4, 2017

Published: September 7, 2017

Copyright () 2017 by authors and Scientific Research Publishing Inc.

This work is licensed under the Creative

Commons Attribution International

License (CC BY 4.0).

http://creativecommons.org/licenses/by/4.0/

\begin{abstract}
The microstructure and hardness on and below the surface of Cr-Mo steel (SCM435) treated by water jet peening (WJP) were investigated using scanning electron microscopy and micro Vickers hardness measurements. The change of the surface residual stress caused by the WJP treatment influenced the surface microstructure and surface hardness of the SCM435 steel. Cementite in the pearlite phase tended to protrude as the duration of WJP was increased. Voids were formed in the area $0.5-1.0 \mathrm{~mm}$ below the surface and also at grain boundaries between ferrite and pearlite grains, whereas no voids were formed in the depth range from 2.0 to $3.0 \mathrm{~mm}$ below the surface.
\end{abstract}

\section{Keywords}

Water Jet Peening, Cr-Mo Steel, Surface Reforming, Microstructure, Voids

\section{Introduction}

Structural machine alloy steels have been used for a wide range of machine parts, mainly automobile parts. However, improvement of the fatigue characteristics of these alloy steels by conventional surface modification used at present is not always satisfactory, because the environment of use for such materials becomes increasingly severe. To solve this problem, the development of surface treatments and their practical application are required. As one method, the authors had a particular focus on the use of water jet peening (WJP) [1] [2] [3]. In the WJP process, high pressure occurs when a cavitation caused by high pressure water jetted from a nozzle collapses on the metal surface. This impact pressure results in slight plastic deformation of the surface layer and generates compressive residual stress by an elastic restraining force from the lower layer portion and the surroundings. When the compression force is converted to compression 
deformation, the deformation returns to its original state after cavitation collapse; however, if a small amount of plastic deformation occurs, then compressive residual stress is generated after cavitation collapse. Shot peening is generally used to apply compressive residual stress to metallic materials, which can result in macrostrain by compression. However, the collision of shot causes microstrain, such as dislocation and lattice defects, to increase, so that hydrogen can easily enter the metal, which tends to cause hydrogen embrittlement [4]. In contrast, WJP treatment can reduce microstrain for each crystal grain introduced by machining or heat treatment while applying macro distortion [5]. Much research on WJP treatment has been related to the sustainment of compressive residual stress and improvement of the resistance to stress corrosion cracking; however, there are few detailed reports on the internal structure in the depth direction from the surface layer of the specimen after WJP treatment.

In the present study, the microstructure and micro Vickers hardness at and below the surface of WJP-treated Cr-Mo steel (SCM435) were investigated using scanning electron microscopy (SEM) and micro Vickers hardness measurements. In addition, the dependence of the microstructure and hardness on the WJP processing time was also investigated.

\section{Experimental Methods}

The material used for these tests was Cr-Mo steel (SCM435), a structural machine steel, the chemical composition of which is shown in Table 1.

Round bar (rod) specimens were heated at $860^{\circ} \mathrm{C}$ as a solution treatment, followed by quenching. Tempering was performed at $600^{\circ} \mathrm{C}$. The specimens were subsequently cut into rectangular specimens with dimensions of $100 \mathrm{~mm} \times 100$ $\mathrm{mm} \times 3 \mathrm{~mm}$. Figure 1 shows a schematic diagram of the equipment used for

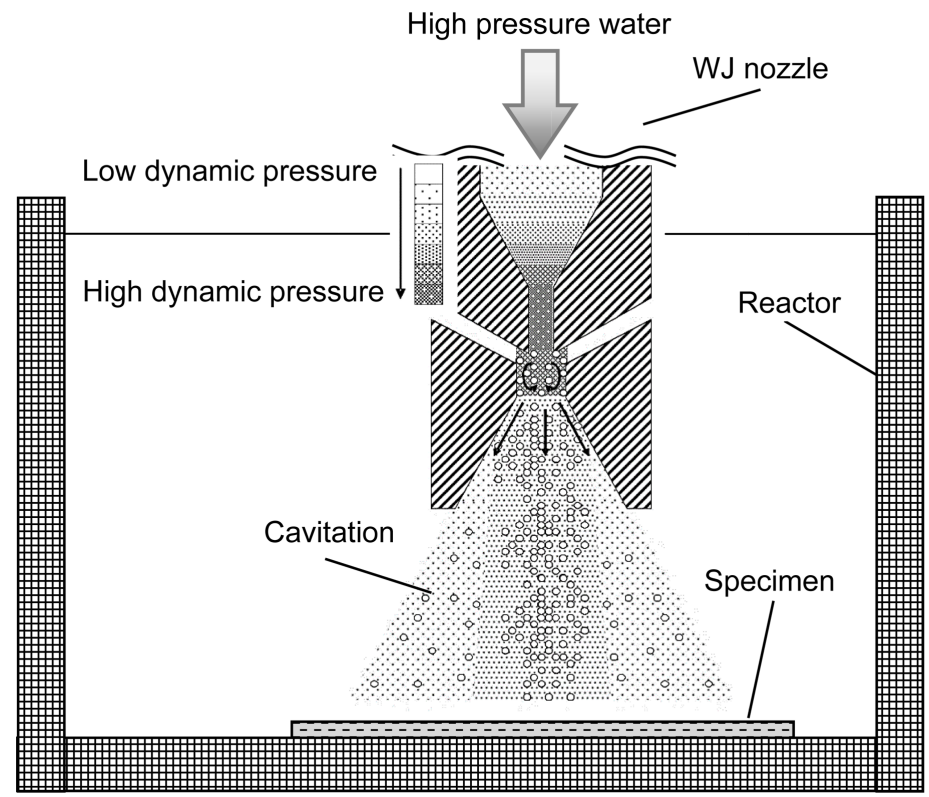

Figure 1. Equipment for surface machining by water jet peening. 
Table 1. Chemical composition of Cr-Mo steel (SCM435).

\begin{tabular}{ccccccccc}
\hline $\mathrm{C}$ & $\mathrm{Si}$ & $\mathrm{Mn}$ & $\mathrm{P}$ & $\mathrm{Ni}$ & $\mathrm{Cr}$ & $\mathrm{Mo}$ & $\mathrm{Cu}$ & $\mathrm{Fe}$ \\
\hline 0.37 & 0.32 & 0.81 & 0.014 & 0.012 & 0.95 & 0.15 & 0.14 & Bal. \\
\hline
\end{tabular}

WJP processing. The nozzle is fixed in water at room temperature and water jets are pumped at a discharge pressure of $35 \mathrm{MPa}$. The nozzle diameter was $0.8 \mathrm{~mm}$. The distance between the nozzle and the specimen was set to be $65 \mathrm{~mm}$. The processing time of WJC was $2 \mathrm{~min}$ and $10 \mathrm{~min}$. Residual stress was measured by the full width at half maximum method and the peak top method from the (211) lattice spacing strain using $\mathrm{Cr} \mathrm{K} \alpha \mathrm{X}$-ray diffraction (XRD; MSF-3M, Rigaku Corporation). Micro Vickers hardness tests were performed at room temperature under a load of $1.96 \mathrm{~N}$ for a loading duration of $10 \mathrm{~s}$. The hardness measurements were averaged for eight values after the minimum and maximum of ten measurements were removed. In addition, hardness measurements near the surface after processing were performed after slight mechanical polishing to remove oxide film and peening marks formed during processing. Microstructure observations were conducted using optical microscopy (OM) and scanning electron microscopy (SEM; S-4800, Hitachi). The specimen for observation was corroded in $5 \mathrm{vol} \%$ Nital etchant.

\section{Results and Discussion}

To further increase the compressive residual stress generated after WJP processing, the specimen surface was first subjecting to hard grinding, which imparted tensile residual stress. Compared to when no tensile residual stress is applied, the compressive residual stress is considered to increase after processing by a shakedown effect. These measurements of residual stress were conducted in a state without corrosion on the specimen surface after each processing, and were performed parallel to the grinding direction of the as-received specimen. Tensile residual stresses of $+202 \mathrm{MPa}$ (half width method) and $+179 \mathrm{MPa}$ (peak top method) were applied to the unprocessed specimen. After WJP processing, the residual stress was -361 MPa (half width method) and -394 MPa (peak top method) after a processing time of $2 \mathrm{~min}$, and $-308 \mathrm{MPa}$ (half width method) and $-313 \mathrm{MPa}$ (peak top method) after processing for $10 \mathrm{~min}$. Tensile residual stress was imparted in the grinding direction of the specimen not subjected to WJP processing, while compressive residual stress was imparted in the vertical direction. As the processing time elapsed, the compressive residual stress decreased. Compressive residual stress is generated when the specimen surface is compressed by the pressure from cavitation collapse because MJ pushes out in the lateral direction, which leads to plastic deformation around the area that is elastically constrained from the surroundings. It is considered that the specimen surface hardens considerably due to this plastic deformation.

Figure 2 shows the change in the micro Vickers hardness for each processed surface with respect to the depth direction, but not including the oxide film and 


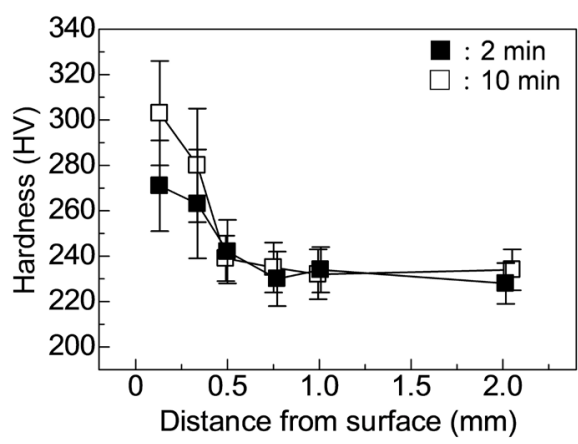

Figure 2. Hardness changes of the specimen after WJP treatment from surface to interior.

peening marks. The hardness of the near-surface region in the unprocessed specimen was $246 \mathrm{HV}$. The hardness distribution of the unprocessed specimen remained unchanged in the depth direction. It is considered that the unprocessed specimen is not significantly influenced by the strong surface grinding that was performed to impart tensile residual stress. The hardness in the near-surface region of the WJP-processed specimen was $272 \mathrm{HV}$ after processing for $2 \mathrm{~min}$ and $303 \mathrm{HV}$ after processing for $10 \mathrm{~min}$. The hardness decreased at a depth of ca. 0.5 $\mathrm{mm}$ from the surface layer. Therefore, it is considered that the compressive stress field reaches a depth of ca. $0.5 \mathrm{~mm}$ from the surface.

Figure 3 shows an SEM image of the specimen surface after WJP processing for $2 \mathrm{~min}$. This SEM observation was performed after a sufficient amount of the surface oxide layer and peening marks were removed. The microstructure of the unprocessed specimen was simple with only pearlite and ferrite evident. Pearlite and ferrite were also observed in various processed specimens, as well as the unprocessed specimen. The shape of the ferrite grains did not change; however, the lamellar structure of the pearlite was bent and kinked bands were formed, which was very similar to a cold-rolled texture.

Apart from the microstructure shown in Figure 3, some circular products, as shown in Figure 4, were confirmed. These products are distributed in large numbers on the specimen surface, and the sizes and shapes are different. The surroundings of these products are flaked, as shown in Figure 4(b), and products where the interior is raised and where the inside was broken, as shown in Figure 4(c), were observed. The products shown in Figure 4 were observed at the surface of the WJP specimen after processing for $10 \mathrm{~min}$.

Figure 5 shows SEM images of these products. Despite the large number of pearlite layered structures remaining in Figure 5(a), one region was a flat surface with indentations inside. Figure 5(b) shows an enlargement of the inner recess, in which cementite is sparse. For products shown in localized regions in Figure 4 or Figure 5, we could not identify whether these products were produced by instantaneous repetitive applied stress or by the successive collision of air bubbles in the same location during WJP. Figure 5(c) shows a different location from that in Figures 5(a) and Figures 5(b), and cementite was observed protruding from the pearlite structure. The cementite products protrude and 


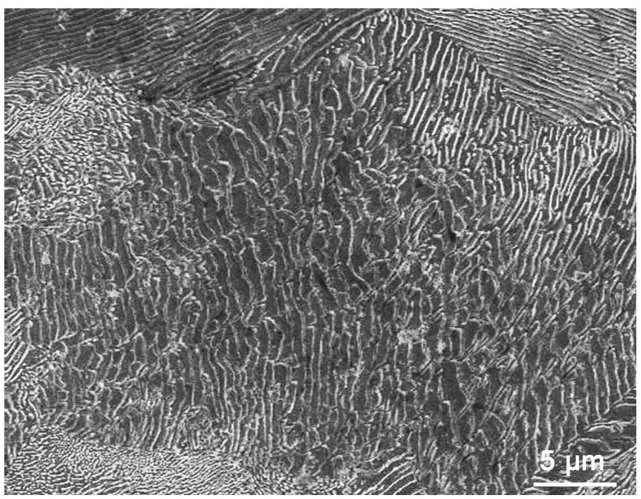

Figure 3. SEM image of specimen surface after WJP treatment for $2 \mathrm{~min}$.
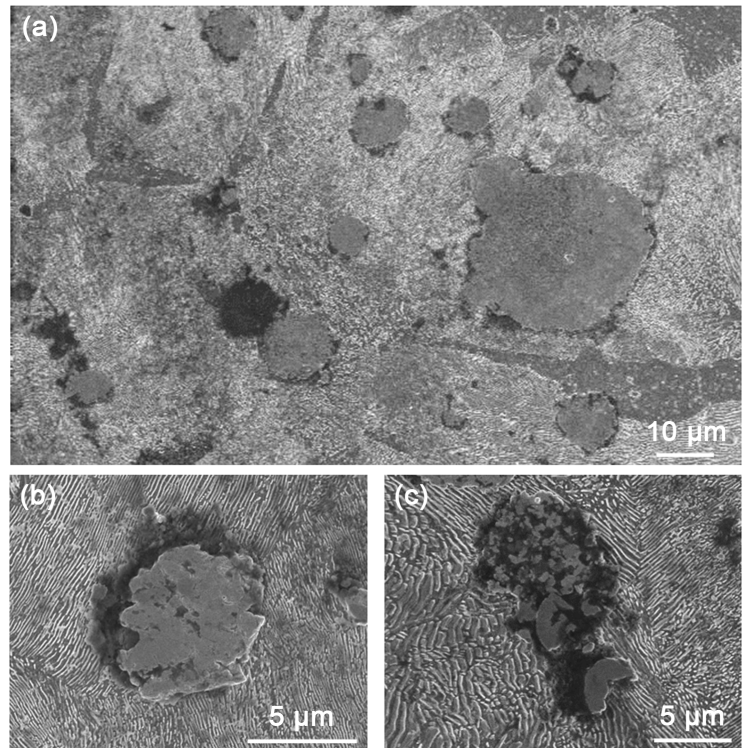

Figure 4. (a) SEM images of the specimen surfaces after WJP treatment for 2 min; (b) and (c) are one enlarged images of the products in (a).
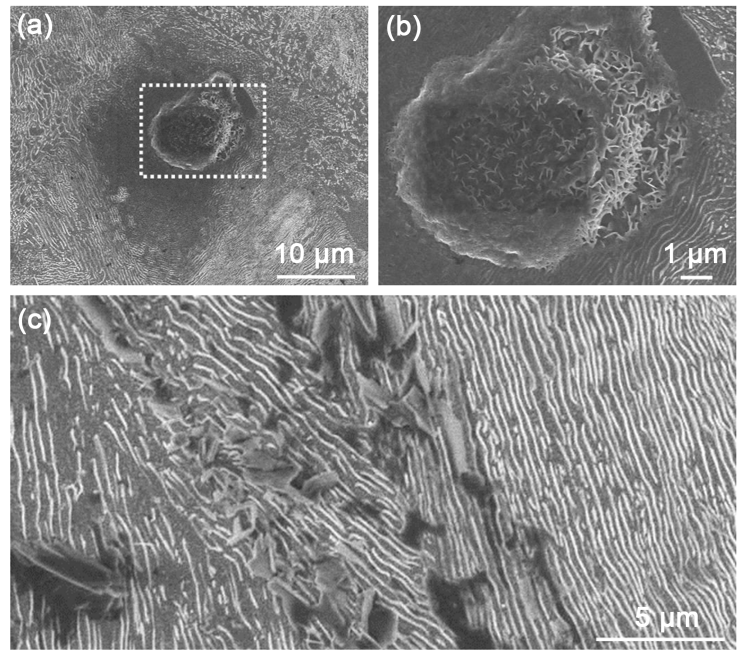

Figure 5. (a) SEM images of specimen surface after WJP treatment for 10 min; (b) Enlargement of the dashed box region in (a); (c) Product of pearlite interior. 
cross within the pearlite interior and then partially disappear were observed in the cementite interior. Any cementite protrusion crossing the pearlite grain is finished in the ferrite part. This phenomenon was observed over the entire pearlite structure.

Figure 6 shows SEM images of the specimen side in the vicinity of the surface after each WJP processing time. When the processing time is longer, the processed surface is rough and the width of the lamellar layers is narrowed. The increase in hardness in the vicinity of the surface by WJP processing is considered to be due to the narrow spacing of the pearlite lamellar layers.

Figure 7 shows an SEM image of a specimen side after WJP processing for 2 min. This observation was performed at a depth of approximately $0.5-1 \mathrm{~mm}$ from the surface. Deformation of the lamellar structure within pearlite was observed at depth as well as at the surface. Overall, the lamellar layers of pearlite had a collapsed shape, and the ferrite grains were elongated.
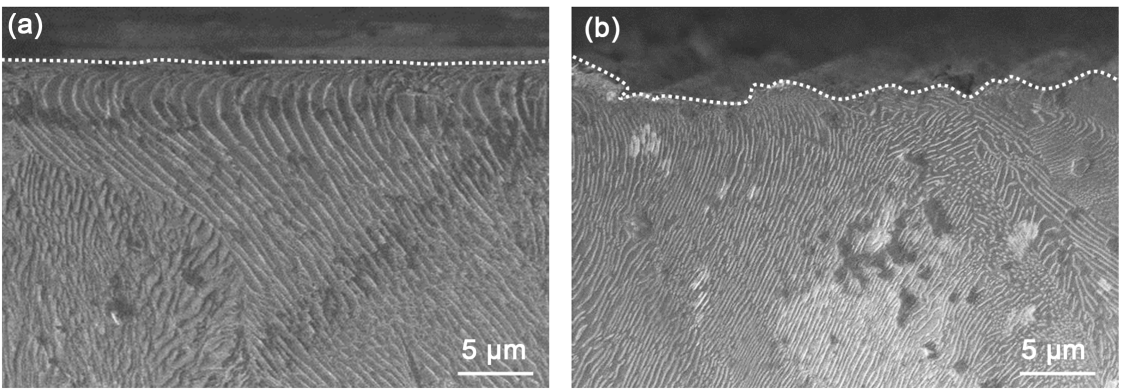

Figure 6. SEM images of the specimen side after WJP treatment for (a) $2 \mathrm{~min}$; (b) $10 \mathrm{~min}$. The dashed line indicates the surface of specimen.

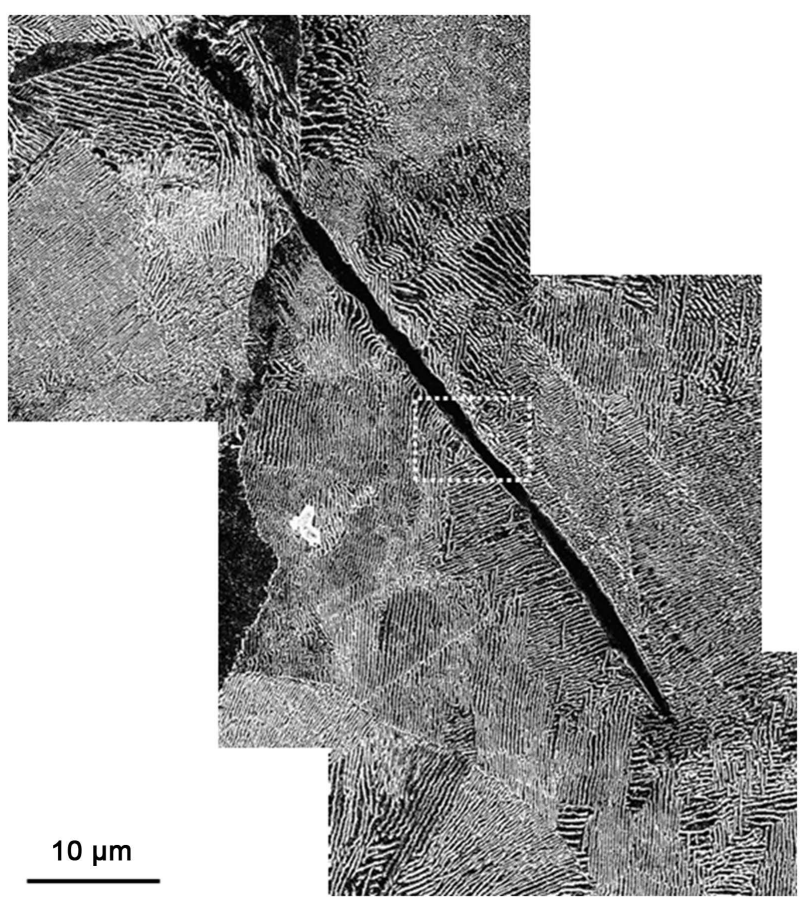

Figure 7. SEM image of the specimen side after WJP treatment for $2 \mathrm{~min}$. 
An enlarged view of the dashed box marked in Figure 7 is shown in Figure 8. Void formation was observed in and around ferrite grains. It is considered that this is not due to compressive stress on the surface but voids were formed by an increase in internal tensile stress. In addition, voids are mainly formed at grain boundaries where ferrite and pearlite are in contact. Only local observation was possible by SEM, but such microstructures were distributed over many other areas of the specimen.

Voids were also observed in the side at depths of 0.5 to $1 \mathrm{~mm}$, even if WJP processing was performed for $10 \mathrm{~min}$. The number of voids was increased compared with the specimen processed for $2 \mathrm{~min}$, and in some cases the voids were connected and cracks were observed. No voids or cracks were observed at depths of approximately 2 - $3 \mathrm{~mm}$ from the surface. Therefore, WJP processing imparts compressive residual stress without changing the properties of the material surface. However, voids and cracks are likely to be formed at grain boundaries where ferrite and pearlite grains are in contact within the specimen bulk after WJP processing. For conventional WJP processing, while macro distortion is introduced, micro strain for each crystal grain introduced by machining or heat treatment can be reduced. In recent progress of WJP technology, the pressure applied to the specimen surface has increased due to microjet deformed part of bubbles and control of the shock wave caused by bubble growth again within a short time [6]. High compressive residual stress is applied to a specimen surface to improve fatigue characteristics; however, the increase in the pressure applied to the specimen surface is likely to produce micro strain in the form of dislocations and lattice defects in the internal structures, similar to that with shot peening in exchange for high compressive residual stress, which could then cause hydrogen embrittlement or delayed fracture. In WJP technology, there are no particular problems, even if voids or cracks occur internally, depending on the specimen being processed. However, it is expected that cracks would gradually increase from internal defects in those parts subjected to repeated external stresses, which could lead to failure. Further improvement of MJ and shockwave control, and further technical development are thus necessary.

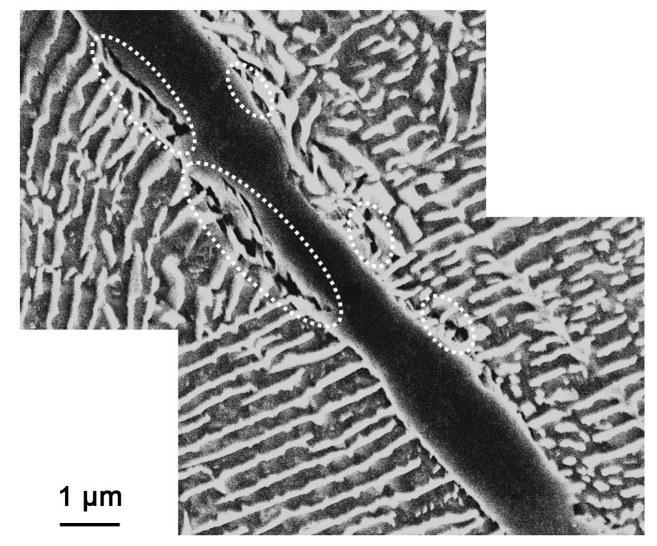

Figure 8. Enlargement of the dashed box region in Figure 7. The dashed line indicates the voids. 


\section{Conclusion}

The WJP-treated specimens were improved from tensile residual stress to compressive residual stress. The microstructure of the WJP processed specimen revealed the appearance of cementite protrusions in pearlite grains at the specimen surface, and voids tended to occur in the depth region of $0.5-1 \mathrm{~mm}$ from the topmost surface. Moreover, voids were not observed at depths of $2-3 \mathrm{~mm}$ from the surface.

\section{Acknowledgements}

This work was supported by the "Innovative Science and Technology Initiative for Security" program of the Acquisition, Technology \& Logistics Agency (ATLA) of Japan.

\section{References}

[1] Saitou, N., Enomoto, K., Kurosawa, K., Morinaka, R., Hayashi, E., Ishikawa, T. and Yoshimura, T. (2003) Development of Water Jet Peening Technique for Reactor Internal Components of Nuclear Power Plant. Journal of Jet Flow Engineering, 20, 4-12.

[2] Yoshimura, T., Hashiwata, Y., Kanbara, T., Sato, K. and Takarayama, N. (2006) Study on Purification of Ballast Water Using Cavitation Jets Induced Steam Condensation. Journal of Jet Flow Engineering, 23, 4-13.

[3] Yoshimura, T., Tanaka, K. and Yoshinaga, N. (2016) Development of Mechanical-Electrochemical Cavitation Technology. Journal of Jet Flow Engineering, 32, 10-17.

[4] Brass, A.M., Chene, J., Anteri, G., Ovejerogarcia, J. and Castex, L. (1991) Role of Shot-Peening on Hydrogen Embrittlement of a low-Carbon Steel and a 304 Stainless-Steel. Journal of Materials Science, 26, 4517-4526. https://doi.org/10.1007/BF00543675

[5] Soyama, H. and Yamada, N. (2008) Relieving Micro-Strain by Introducing Macro-Strain in a Polycrystalline Metal Surface by Cavitation Shotless Peening. Materials Letters, 62, 3564-3566. https://doi.org/10.1016/j.matlet.2008.03.055

[6] Ishibashi, R., Hato, H., Yoshikubo, F. and Miyazaki, K. (2016) Analytic Examination of Mechanism for Compressive Residual Stress Introduction with Low Plastic Strain Using Peening. Mechanical Engineering Journal, 3, 16-00300. https://doi.org/10.1299/mej.16-00300 
Submit or recommend next manuscript to SCIRP and we will provide best service for you:

Accepting pre-submission inquiries through Email, Facebook, LinkedIn, Twitter, etc. A wide selection of journals (inclusive of 9 subjects, more than 200 journals)

Providing 24-hour high-quality service

User-friendly online submission system

Fair and swift peer-review system

Efficient typesetting and proofreading procedure

Display of the result of downloads and visits, as well as the number of cited articles Maximum dissemination of your research work

Submit your manuscript at: http://papersubmission.scirp.org/

Or contact msa@scirp.org 